\title{
Cellulose Bio-ink on 3D Printing Applications
}

\author{
Ramesh Ganpisetti ${ }^{1, *}$, Aikaterini Lalatsa ${ }^{2}$ \\ 'School of Pharmacy, University of Portsmouth, Portsmouth, UNITED KINGDOM \\ ${ }^{2}$ School of Pharmacy and Biomedical Sciences, Faculty of Science, University of Portsmouth, Portsmouth, UNITED KINGDOM.
}

\begin{abstract}
Nanocellulose polymers have played a vital role in biomedical applications and the medical field as a whole and made possible with 3D bio-ink printing. This achievement has made it easy for skin grafting, organ transplants and cancer screening and treatment. The many available thermoplastics are being replaced with cellulose from wood, pulp and plants, some of the cellulose polymers covered in this paper are Nanocellulose (CNF), nanofibers (CNC), Bacterial cellulose and many more cellulose polymers as discussed in the preceding chapters. This review also details advancements in modifications that have been done in cellulose polymers to make them more and more effective in the medical field that each day is facing challenges. The introduction section, chapter one, brings out the core issues of the paper introducing bio-ink which is further discussed in detail in chapters two and three, information on cellulose, its sources and polymer can be obtained from both chapters one and two. The aims and objectives of this writing are to review the journey that 3D bio-ink printing
\end{abstract}

of cellulose Polymers, particularly Nano polymers of CNC and CNF, have taken since their inception in Sweden. This paper blends with previous information and current findings, uses and discoveries on the 3D bio-ink printing of nanocellulose. It also endeavors to ascertain how 3D printing has influenced the application of 4D bioprinting in its advanced stages.

Key words: Nanocellulose, CNC, CNF, 3D bio-ink printing, Nanocrystals, Nanofibers

\section{Correspondence}

Mr. Ramesh Ganpisetti

School of Pharmacy University of Portsmouth, Elm grove, Flat 3, 55 New Buildings, PO 51JF, UNITED KINGDOM.

Phone: 4407459955922

Email: up950648@myport.ac.uk

DOI: 10.5530/jyp.2021.13.1

\section{INTRODUCTION}

\section{Cellulose is a polymer, sources and Structure}

Cellulose $\left(\mathrm{C}_{6} \mathrm{H}_{10} \mathrm{O}\right)$ is an organic compound linear in structure and a long-chained carbohydrate polymer with glucosidic linkages. It is an essential component in the plant cell wall and used as indigestible fiber in the human diet. It is a polysaccharide in nature since it is made up of sugar molecules. As a polymer naturally, cellulose is contained in wood, paper and cotton with wood and cotton containing fibrous cellulose (Table 1). ${ }^{1,2}$ The first synthetic polymers were made from cellulose. These synthetic polymers include cellulose nitrate, cellulose acetate and rayon. Cellulose is considered the best biopolymer in nature, also as a replacement for petrochemical products due to being a renewable, eco-friendly resource. ${ }^{3}$ Its modifications have resulted in products that have durable mechanical power. Most are biodegradable in the environment, making them be in high demand in the current market. Chemical change of cellulose has resulted in the manufacturing of multipurpose materials. This Modification is through the esterification of the hydroxyl groups - $\mathrm{OH}$ - in the cellulose. ${ }^{4}$ Chemical Modification of Cellulose leads to the production of Nanocrystals (NCC), nanofibers (CNF) and many other thermoplastics of cellulose.

Cellulose is vital in cell walls of higher plants. It's also a natural organic polymer that of late has many used in paper industries, textile and pharmaceutical applications. It has to lead to research and further studies in it to maximize its uses as a green environmental-friendly producer. Cellulose is obtained mostly from plants and wood. ${ }^{5}$ It can also be obtained from food waste. Majorly, cellulose constitutes plant fiber that provides mechanical strength to woody stems. Its pure form can be found in cotton seeds where its $90 \mathrm{wt} \%$, also as lignified Cellulose, Hemicellulose and pectin. All of this can be extracted and processed, ${ }^{6}$ posits that isolation of cellulose must occur before its production, Treatment or Modification has occurred.

\section{Modification of Cellulose and applications}

Cellulose is a linear polymer with repeating D-glucopyrase units, also known as AGU (anhydroglucose unit). Glucosidic bonds link this AGU's. Degree of polymerization (DP) varies depending on origin and extraction methods. It can also vary with the amount of wood pulp ranging from $800-10000$ which can contain either 300 or 1700 AGU's Usually DP is average and for each, three hydroxyl groups are present. After polymerization, they rearrange themselves with fibrils of high orders in them influencing characteristics like texture, density and other properties. ${ }^{9}$ Studies on cellulose modification didn't start yesterday but rather in the 1880s. During Gunpowder warfare, cellulose nitrate was made accidentally by treating Cellulose with nitrate. Used as explosives. Later on, celluloid replaced cellulose nitrate because of the dangers the later posed. Cellulose acetate (CA) later in 1865, replaced the two. It has led to broad spread research and study on its modifications, improvement and applications. ${ }^{10}$

For instance, cellulose from wood is isolated using a technique called pulping. Here process like Kraft/sulfate process and or Sulfite process are done. Cellulose is separated from lignin and hemicellulose. Pulps of various strength and property cellulose are obtained. Paper pulp cellulose for making paper can be obtained here, also dissolving gride pulp cellulose for regenerated Cellulose and its derivatives can be obtained $^{11}$ Here the derivatives of Cellulose can be used in making pharmaceutical products and the making of polymers that can be used in bio-ink Printing. ${ }^{12}$ 
Before Modification, it is must be clear that cellulose is insoluble in water and organic solvents because of its macromolecular nature with high DP. Also, due to its thermodynamics and hydroxyl groups that make its $\mathrm{C}$ and $\mathrm{H}$ atoms to have low hydrophobic interactions, derivatizing and non-derivatizing solvents are hence used to treat the cellulose. Cellulose applications depend on cellulose modification. Reactive groups in cellulose are the hydroxyl groups. They are suitable for a variety of modification techniques. Chemical Modification is one of the techniques commonly used. It results in different cellulose derivatives with many applications. The reaction can occur at C atoms of AGU's by nucleophilic displacement.

Oxidation of cellulose to form carboxyl groups provides a source for making cellulose derivatives. Some of the nanocellulose derivatives are nanocrystals (NCC), nanofibrils (CNF) bacteria nanocellulose. ${ }^{13}$ Materials produced depends on the source and treatment of cellulose. The availability of thermoplastics in Nanocellulose has led to research and studies that have helped in biomedical applications like 3D bio-ink since the nanocellulose can be used as modifiers for inks. The Nanocellulose has muscular mechanical strength, their ability to support cells and prevent pore damage attributes that also aid in implants modifications and regeneration. ${ }^{14}$

On the other hand, Nanofibers (CNF) consisting of Nanofibrilliated cellulose (NFC) and Nanofibrils are obtained by mechanical distortion and dismantling of regions of cellulose chains in its chemical Structure ${ }^{15}$ Nanocellulose is also used in cancer therapy treatment. Though still in advanced stages of research and studies, medial practices like tissue engineering, skin grafting and regeneration and the use of bacterial cellulose as drug carriers are some of the processes taking place in cancer treatment ${ }^{16}$ a significant mile storm in the medical field to try and eliminate this monster called cancer. The breakthrough though not complete, has borrowed the uniqueness of Nanocellulose and 3D bio-ink Printing to help in biomedical application.

Nanocellulose can be obtained from cellulose sources of wood, plants, paper and cotton through a top-down process where different varieties of Nanocellulose are obtained because cellulose has qualities that differentiate itself from other synthetic polymers, such as polyfunctionality, chain stiffness and sensitivity. Several research pieces have been carried out on cellulose to understand its functionality and properties. Done by Hermann Staudinger, who tried to isolate Cellulose through acetylation and deacetylation. In his findings, he found out that the glucose linkage in Cellulose was attached repeatedly giving the cellulose its polymer properties. ${ }^{17}$

Micro fibrillated cellulose and bacterial cellulose are useful in the production of bio-nanocomposites. This nanocellulose can be modified using several mechanical processes. They have low density and are biodegradable. Equally, they have high mechanical strength. The only disadvantage nanocellulose has is its automatic extraction from cellulose and they also have high energy consumption. ${ }^{18}$ Pretreatment of the micro fibrillated cellulose helps in overcoming such disadvantages. The surface modification reduces the mechanical problems of the microfibril cellulose.

Nanocelluloses that include cellulose nanocrystals and Nano fibrillated celluloses with low as well as high aspect ratio, are promising bio-founded materials that are prepared from plant cellulose such as wood through mechanical cropping in water in absence or presence of pretreatments. However, its extraction is limited due to being hydrophilic, thus restricting its usage. Enzymatic surface modification is done on Nanocellulose to help make it perfect even with its hydrophilic properties.

Chemical Modification of nanocellulose is done to improve the properties of cellulose through grafting in or grafting off of substrates made of either nanocrystals or Nano whiskers. The grafting process starts with the initiator, mostly monomer concentrations. Here the acid hydrolysis enables the hydrolysis groups to cover the upper surfaces of the cellulose. When the surface of the cellulose occurs, the cellulose's mechanical properties facilitate the compatibility of Cellulose. ${ }^{19}$

In a surface modification of nanocellulose, two main procedures are done, namely compatibilization and polymerization. In the former, a reactive reagent is attached at the surface of cellulose. A mobility agent that needs two functional groups is attached to the cellulose surface during polymerization. One of the functional groups reacts with the hydroxyl group. In contrast, the other group attaches to the covalent bonds of the polymer matrix, thus helping in the mechanical strength of the nanocellulose when doing its function. Polymerization can be done in different ways like graftings, radical reactions, or organometallics. ${ }^{20}$

Reagents used in the Modification of nanocellulose are succinic anhydrous, Phenyl isocyanate and isoprene. Nanocelluloses have many applications due to their remarkable mechanical properties since they can be changed into polymerics using methods like melt-compounding, solvent casting and in-situ polymerization. Of the three methods, solvent casting is the preferred method for research purposes. It mixes with polymer matrix in a suitable solvent. Then the mixture is cast in a recipient forming a nanocomposite film through evaporation of the solution.

However, the significant setback of processing CNCs through thermalmechanical compounding causes low thermal stability due to sulfate groups present on the surface. These groups generate corrosive species upon heating, which induce cellulose chain degradation. Calling for an alternative method that facilitates the production of high-content cellulose nanostructured composites. However, combining a high fraction of the CNF network with a hydrophobic matrix has been mostly unexplored. Yet, with the advancement in technology, this can be cracked. The CNF network in the form of nano paper can be repaired by spraying the CNF liquid suspension followed by a solvent exchange and supercritical carbon dioxide $\left(\mathrm{CO}_{2}\right)$ suspension. This process allows the removal of the solvent without cellulose degradation as a critical temperature and the $\mathrm{CO}_{2}$ pressure is $31^{\circ} \mathrm{C}$ and $7.4 \mathrm{MPa}$, respectively. Hence preserving the CNF network, which has an internal surface area as high as $480 \mathrm{~m}^{2} \mathrm{~g}^{-1} \cdot{ }^{21}$

Nanocellulose CNF is the most important and widely used cellulose since the processes of Modification of cellulose perfectly fits them. They are also easily obtained from cellulose either through chemical modification or surface treatment using suitable solvent materials. Its availability has resulted in many breakthroughs in the medical field as some of its uses like TERM (Tissue engineering and regenerative medicine and biomedical applications, cartilage regeneration, tissue repair, skin grafting, wound dressing).

\section{MATERIALS AND METHODS}

To this study, a literature review of articles published between 2016 and 2020 was carried out, mainly through the PUBMED and LILACS databases. Thus, articles from systematic reviews, clinical trials, in vitro and in vivo studies were selected in English languages. We selected 65 articles related to the theme in question.

\section{Ideal bio-inks 3D printable and characteristics of 3D Printing}

Bio-inks materials can be used to make artificial living tissues by using a $3 \mathrm{D}$ printing technique. The cells being used here contain extra materials that seal them. The ink being used is usually composed of the cells being made. Some of the bioink techniques in use are selective laser sintering (SLS), Injet bioprinting, direct ink writing (DIW), fused 
deposit modelling (FDM) and laser infused forward transfer (LIFT), stereolithography (SLA) etc. $^{22}$

Currently, there are more advanced methods of $3 \mathrm{D}$ Printing that is being applied in Printing of tissues and organs. ${ }^{23}$ Acoustic Printing, Microwave bioprinting, Electro-hydrodynamic printing, pneumatic bioprinting are some of the methods used. Scientists have been exploring ways of using $3 \mathrm{D}$ bio-inks printing which increases printing speed at the same time retaining cell properties. ${ }^{24}$ This scientist found out that specific requirements are to be in place for a 3D bio-inks printing these requirements go hand in hand with the characteristics and properties of right 3D bio-inks materials. Types of 3D bio-inks are summarized in Table 2.

Bio-ink is affected by many factors that determine its characteristics. This technique is dependent on single material printing, though, with current research, many materials have been recommended and are in use already. These materials are usually called biomaterials. Some of these materials are natural, while others are not. Natural biomaterials have the upper hand over synthetic materials over time most of the characteristics mentioned in the Table 3 are obeyed by natural biomaterials. ${ }^{25}$ Difference between natural biomaterials and synthetic biomaterials is given in Table 4 .

A challenge with crosslinked printable materials or generally Synthetic biomaterials is that they should be regulated at body temperatures of between $37^{\circ} \mathrm{C}$ and below to minimize side effects on cells during biomedical applications. ${ }^{26}$ The year 2016 led to a range of commercial inks that were compatible with commercial printers, Inks containing natural polymers like chitason, collagen and gelatine have been in use with positive results so far. ${ }^{27}$ Further findings and research in the fields have helped in making it easier for bioinks to give these beneficial results in biomedical applications. Tissue engineering, regenerative medicine (TERM), Treatment of cancer and some other biotechnology that add insight on bio-ink. According to ${ }^{28} 3 \mathrm{D}$ bio-ink printing is in demand in

Table 1: Structure of cellulose and sources

\begin{tabular}{cccc}
$\begin{array}{c}\text { Structure of } \\
\text { cellulose }\end{array}$ & Sources of cellulose & $\begin{array}{c}\text { Uses of } \\
\text { cellulose }\end{array}$ & Reference \\
\hline Wood, Living plants, & $\begin{array}{c}\text { In paper } \\
\text { industries, }\end{array}$ & 7,8 \\
Organic waste \\
biomedical \\
applications
\end{tabular}

Table 2: Types of 3D bio-inks

\begin{tabular}{cc}
\hline Types of 3D bioinks & Comparison \\
\hline Direct ink writing (DIW) & $\begin{array}{c}\text { Hydrogel removed to obtain 3D } \\
\text { structures in the presence of carries } \\
\text { or not } \\
\text { Inkjet } \\
\text { Cell suspensions deposited as high } \\
\text { shear rates }\end{array}$ \\
Lift technology & $\begin{array}{c}\text { Curing doesn't affect live cells after } \\
\text { Printing }\end{array}$ \\
& $\begin{array}{c}\text { Laser-focused on laser absorbing } \\
\text { material which builds pressure to } \\
\text { release ink layers }\end{array}$ \\
\hline
\end{tabular}

biotechnology, particularly in the regeneration of tissues, organs, or cells to facilitate the restoration of normal biological functions.

Bio-ink has a high reproductivity and better control of fabricated and modified materials than other techniques like the use of thermoplastics. After their deposition, they can still be maintained by removing them through small openings of the printers in the form of filaments. These filaments can even be used again. Natural deviations must be bioactive. Bioinks are also utilized in the construction of collagen and cartilage, restructuring and creation of skin patches and many other body parts. Our focus is on nanocellulose that is best in chemical acid hydrolysis.

Previously, skin grafting, regeneration and some advanced therapy were never in existence, but with the use of 3D bio-ink printing, this has been made possible. 3D technology allows the production of many complex structures through the bottom-up method ${ }^{29} 3 \mathrm{D}$ bio-ink allows biocompatibility and linkages between the gel mixed with the living cells. When this bio-ink is printed, it is said to be 3D Printing. Bio-ink materials determine their applications and uses. There are many bio-ink materials in use today. ${ }^{30}$ Some of the materials are shown in the Table 5.

Other examples of bio-ink based materials are; Fibril based bioinks, cellulose based bio-inks, Silk based bio-inks, Extracellular matrix (ECM) based bio-inks, cell aggregation based bioinks, synthetic-based bio-inks. This study deals with cellulose-based bio-inks. As stated earlier, cellulose based bio-ink materials have led to the production of Nanocrystals, Nanofibrils and Nanocellulose.

\section{Applications of different Nanocellulose in Biomedical applications}

\section{Cartilage treatment and growth}

Nanocellulose in wood that contains $2.5 \%$ CNF having been alginate with $\mathrm{CaCl}_{2}$ for cartilage tissue growth. As it is known, cartilage problems, when allowed to be severe, can cause serious clinical problems. Traditionally, it was difficult to detect and treat cartilage problems. With cell growth and tissue maturity being a requirement in growth, Biolink made it possible to use alginate $\mathrm{CaCl}_{2}$ combined with Nanocellulose to regenerate cells are for grafting and treatment. A milestone in the medical field as cartilage replacement makes this possible as Alginatenanocellulose combination can allow printability. Several advanced research on how to improve on already discovered techniques of cartilage repair and growth using 3D bio-ink printers.

Table 3: Characteristics of bio-inks

\begin{tabular}{cc}
\hline Characteristics of bio-inks & Reasons for the characteristics \\
\hline Biocompatibility & $\begin{array}{c}\text { Prevents undesirable effects with } \\
\text { the cell }\end{array}$ \\
Permeability & $\begin{array}{c}\text { Use of volumetric bioink Printing to } \\
\text { reduce the time of Printing } \\
\text { Allow interaction with cell } \\
\text { environment }\end{array}$ \\
Tissue regeneration & $\begin{array}{c}\text { To allow the growth of cells and } \\
\text { tissues }\end{array}$ \\
In situ gelation & $\begin{array}{c}\text { Allow mechanical strength and } \\
\text { support }\end{array}$ \\
Biodegradable & $\begin{array}{c}\text { Must be able to biodegrade to allow } \\
\text { regeneration of cells }\end{array}$ \\
Viscoelasticity & $\begin{array}{c}\text { Allows similarities between inked } \\
\text { materials and surrounding cell } \\
\text { environment }\end{array}$
\end{tabular}


Table 4: Comparison between Natural Biomaterials and Synthetic Biomaterials

i) Advantages of natural biometrics over synthetic biometrics

Biodegradable

Compatible with surrounding cells

Self-assembling

Mimics the extracellular matrix

ii) Advantages of synthetic biomaterials over natural biomaterials

Synthetic biomaterials for 3D Printing

Mechanical stability is controlled

Responds to $\mathrm{pH}$

Responds to Temperature

Has photo crosslinking abilities
Table 5: Bio-ink Material sources

\begin{tabular}{cc}
\hline Bio-ink material & Summary notes \\
\hline Agaron based bio-inks & $\begin{array}{c}\text { From seaweeds, gel properties make it } \\
\text { desired due to its mechanical strength and } \\
\text { biocompatibility, supports epithelial and } \\
\text { fibroblasts growth. }{ }^{31}\end{array}$ \\
Alginate based bio-inks & $\begin{array}{c}\text { Natural biopolymer from brown algae, less } \\
\text { inflammatory effects, forms sodium alginate } \\
\text { matrix, Important in TERM }\end{array}$ \\
Collagen-based bio-inks & Biocompatible, crosslinking using temp, pH \\
or riboflavin & \\
Hyaluroni based bio-inks & For cartilage and connective tissues.
\end{tabular}

Table 6: The table below shows a summary of the Nanocellulose polymers based biomedical materials

\begin{tabular}{|c|c|c|c|c|c|c|c|}
\hline Nanocellulose & $\begin{array}{l}\text { CNF/CNC } \\
(\%)\end{array}$ & Composition & Sources & Viscosity & $\begin{array}{l}\text { Length } \\
(\mathrm{nm})\end{array}$ & Application & Reference \\
\hline $\begin{array}{c}\text { Amorphous } \\
\text { Nanocellulose (ANC) }\end{array}$ & $\begin{array}{c}0.71 \% \\
\text { nanocellulose }\end{array}$ & $\begin{array}{c}\text { Microcrystalline } \\
\text { pulp, cotton cellulose, } \\
\text { phospholipids }\end{array}$ & $\begin{array}{l}\text { Cotton, Wood } \\
\text { pulp }\end{array}$ & $\begin{array}{l}\text { Viscocity reduces } \\
\text { with increase in } \\
\text { temperature }\end{array}$ & $20-120$ & $\begin{array}{c}\text { Thickening agent, } \\
\text { Carrier of bioactive } \\
\text { substances }\end{array}$ & 34 \\
\hline $\begin{array}{c}\text { Cellulose Nanoyarn } \\
\text { (CNY) }\end{array}$ & $\begin{array}{c}10 \% \\
\mathrm{CNC}, \mathrm{CNF}\end{array}$ & Alginate, sulfite, & $\begin{array}{l}\text { Cellulose and } \\
\text { its derivatives }\end{array}$ & $\begin{array}{l}\text { Elastic at high } \\
\text { temperature }\end{array}$ & $\begin{array}{l}100- \\
1000\end{array}$ & $\begin{array}{l}\text { Food packaging, paper } \\
\text { manufacturing }\end{array}$ & 35,36 \\
\hline $\begin{array}{l}\text { Bacterial Nanocellulose } \\
\text { (BNC) }\end{array}$ & $\begin{array}{c}0.5 \% \\
\mathrm{CNC} \text { and CNF }\end{array}$ & Gel matrix, alginate & $\begin{array}{l}\text { Glucose, } \\
\text { Bacteria }\end{array}$ & Viscous & $10-50$ & $\begin{array}{l}\text { Wound repair, food } \\
\text { industries }\end{array}$ & 37 \\
\hline $\begin{array}{l}\text { Cellulose Nanofibrils } \\
\text { (CNFs) }\end{array}$ & $0.25 \%$ CNF,CNC & Matrix, agrona, sulfite & $\begin{array}{l}\text { Hard, softwood, } \\
\text { Bacteria }\end{array}$ & Viscous & $20-100$ & $\begin{array}{l}\text { Tissue regeneration, } \\
\text { Food Packaging }\end{array}$ & 38 \\
\hline $\begin{array}{l}\text { Cellulose Nanocrystals } \\
\text { (CNCs) }\end{array}$ & $\begin{array}{c}0.26 \% \\
\text { CNC, CNF }\end{array}$ & Gel matrix, sulfite & $\begin{array}{l}\text { Hard, softwood, } \\
\text { Bacteria. }\end{array}$ & Viscous & $4-70$ & $\begin{array}{l}\text { Cartilage and collagen } \\
\text { repair, Food Packaging }\end{array}$ & 39 \\
\hline
\end{tabular}

\section{Auricular cartilage regeneration}

Happens through tissue engineering or what is known as a TERM (Tissue engineering and regenerative medicine). Here, regeneration of cartilage to treat the disease is done even in clinical cases by restoring and repairing the damaged cartilage. Autologous cartilage grafting to re-establish unique biological and functional properties of tissues. Multipurpose stem cells MSCs are used from either bone marrows or adipose tissues ${ }^{40} \mathrm{It}$ is worth noting that more research in this field is ongoing. The stem cells of MSCs have chondrogenic potentials and proliferative growth and regeneration capacity. They also have transformed growth factors of bone morphogenetic proteins (BMPs) that play a part in this process. Earlier 3D bio-ink had scanty or no information on auricular cartilage regeneration. However, as current easiness to harvest BMP and adipose stem cells (ASCs) derived from the stem cells has made it possible for the reconstruction of auricular cartilage. ${ }^{41}$

\section{Wound dressing}

Traditionally wound dressing was no challenge as it was a standard treatment done in our homes even with the most underqualified relatives, family members and friends, however, with the world wars. Deep wounds needed special care and they needed faster Treatment because the wounded needed to go back into the battlefield. 3D burning printing came in handy to solve this problem. This advancement was not until the late stages of the $19^{\text {th }}$ century and fast-tracked in the $20^{\text {th }}$ century. ${ }^{43}$ A $3 \mathrm{D}$ printer can be deposit skin layers covering large parts of the wound or affected area, then the Bio-ink of the 3D printer fast tracks the healing process of the injury. Here, MSCs cells that promote skin regeneration and growth and, at the same time, reducing scarring of the skin. Initially, it was through skin grafting, where one part of the skin would be removed and grafted on the part of the skin, which led to differences in texture, color and complications of the surface copied to other parts of the skin. With the current wound healing method, the MSCs show similarity in the biological and physical properties of the area on Treatment. 3D bio-inks are essential in wound dressing of more significant parts of the body that develops at a faster rate. ${ }^{44}$ It's important to note that 3D bio-ink Printing helps in Tissue engineering where advancements in TERM have made it possible for organ transplants and tissue regeneration.

\section{Use of Cellulose 3D Bio-ink Printing in Cancer treatment:}

Cancer is a complex disease that up to date research about it is to try and fully understand it. Cancer showing heterogeneous cellular composition cannot show all its stages of initiation, development, metastasis, cellcell interactions and extracellular matrix interactions (ECM) in its 2D or 3D models. That is why the importance of 3D bioink Printing came into play because in $2 \mathrm{D}$ and $3 \mathrm{D}$ extent of tumor and stages. 3D bioink Printing helps in creating high-resolution images that help in the study and treatment of cancer. It helps in the study of cancer genesis, growth and response to cancer drugs. ${ }^{45} 3 \mathrm{D}$ structures imitate an entire tumor by coping with the cells with properties for the type of cancer and stage of the disease. In doing this, the $3 \mathrm{D}$ helps in cancer screening and 
therapy. ${ }^{46}$ The 3D models that are a prototype of ECM cancer cells based on hydrogel, gels with tumor cells. The hydrogels are from collagens like nano collagen. Advantageous from using other synthetic polymers because the 3D hydrogels pick the exact tumor cell to use. Therefore, they show similarity in the biological, physical properties of the tumor cells from the affected area ${ }^{47}$ Nanocellulose polymers based biomedical materials are summarized in Table 6.

\section{CONCLUSION}

It is worth noting that $3 \mathrm{D}$ bio-inks is the future of biomedical applications and biomedical engineering. Its ability to produce and regenerate tissues and organ structures has opened further studies in this field. Currently, commercialization of bio-inks is taking place at a rapid rate with state-of-the-art patient-specific $3 \mathrm{D}$ structures for their urgent medical needs produced at a faster unique way. 3D structures of numerous advantages like flexibility, improved mechanical strength, controlled biodegradability and user-specific have made it possible to transplant, regenerate and cushion any loopholes in the medical field. The materials are also unique. The hydrogel is best in this scenario. Use of hydrogel, selection of different bioinks and their availability is a detailed format in the above chapters.

The use and development of bioinks are still in progress just as the saying education and knowledge never ends or never expires. This knowledge has enabled the introduction of 4D bioinks that are currently in use in some parts of the world. 3D bio-inks has also made strides in cancer treatment and therapy. The 3D bio-inks has enabled the introduction of more unique and easier to understand models' structures of cancer cells, enabling researchers to be able to identify tumour cells, development and nearly all stages of cancer. ECM-based bioinks, decellularized bioinks, cell aggregates or spheroids that showed promising results are being used in the development of functional tissues or organs using 3D bioprinting technology. This technique though requires a large number of specific cells on top of many characteristics and properties. Development of advanced bioprinters which are cheap with high resolution has enhanced prospects further. Appropriate bioinks that satisfactorily meet bioprinting requirements with regards to the mechanical, rheological and biological properties are scanty to date. Creation of new bio-ink materials and the engineering of novel bio-ink formulations are currently significant areas of interest. This document has tried to blend the already known information about bioinks with work in progress discoveries and new ideas in the biomedical field, particularly bioink Printing.

It shouldn't go unnoticed on how bioink has played a more significant part in the biomedical field, with TERM and cancer treatment making significant strides. Since science is evolving daily, many expectations are held particularly on how 3D bio-inks will shape the medical field further. Each day with the discoveries of new diseases, new measures counter the alarming trend. Many scientist's world over are doing their best to incorporate $3 \mathrm{D}$ technology in their practices. Now the medical practice has been made possible and faster since the inception of 3D bioink Printing. The introduction of 4D printing has even taken these expectations much higher.

\section{ACKNOWLEDGEMENT}

The authors would acknowledge Portsmouth University for its support for the work.

\section{CONFLICT OF INTEREST}

The authors declare no conflict of interest.

\section{ABBREVIATIONS}

CNF: Nanocellulose; NC-nanofibers; DIW: Direct ink writing; FDM: Fused Deposit Modelling LIFT: Laser Infused Forward Transfer; LIFT: Stereolithography; TERM: Tissue Engineering and Regenerative Medicine.

\section{REFERENCES}

1. Klemm D, Heublein B, Fink HP, Bohn A. Cellulose: Fascinating biopolymer and sustainable raw material. Adv Mater. 2005;44(22):3358-93.

2. Yim SM, Song JE, Kim HR. Production and characterization of bacterial cellulose fabrics by nitrogen sources of tea and carbon sources of sugar. Process Biochem. 2017;59:26-36.

3. Lauer MK, Estrada-Mendoza TA, McMillen CD, Chumanov G, Tennyson AG, Smith RC. Durable Cellulose-Sulfur Composites Derived from Agricultural and Petrochemical Waste. Adv Sustain Syst. 2019;3(10):1900062.

4. Dong Y, Lu X, Wang P, Liu W, Zhang S, Wu Z, et al. Click-chemical" modification of cellulose acetate nanofibers: A versatile platform for biofunctionalization. J Mater Chem B. 2018;6(28):4579-82.

5. Gilroy KD, Ruditskiy A, Peng HC, Qin D, Xia Y. Bimetallic nanocrystals: syntheses, properties and applications. Chemical Reviews. 2016;116(18):10414-72.

6. Menon MP, Selvakumar R, Ramakrishna S. Extraction and modification of cellulose nanofibers derived from biomass for environmental application. RSC advances. 2017; 7(68):42750-73.

7. Sharma C, Bhardwaj NK. Bacterial nanocellulose: Present status, biomedical applications and future perspectives. Mater Sci Eng C Mater Biol Appl. 2019;104:109963.

8. Zhang X, LiuY, Wang Y, Luo X, LiY, Li B, et al. Surface modification of cellulose nanofibrils with protein nanoparticles for enhancing the stabilization of OM pickering emulsions. Food Hydrocoll. 2019;97:105180.

9. Feng D, Hao J, Liao R, Chen X, Cheng L, Liu M. Comparative study on the thermal-aging characteristics of cellulose insulation polymer immersed in new three-element mixed oil and mineral oil. J Polym. 2019;11(8):1292.

10. Gumrah DA. Nanocellulose and its composites for biomedical applications. Curr Pharmacol Rep. 2017;24(5):512-28.

11. Kargarzadeh $H$, loelovich $M$, Ahmad I, Thomas S, Dufresne A. Methods for extraction of nanocellulose from various sources. Handbook of nanocellulose and cellulose nanocomposites. 2017;1:1-51.

12. Sharip NS, Ariffin H. Cellulose nanofibrils for biomaterial applications. Mater Today Proc. 2019;16:1959-68.

13. Manzetti S, Gabriel JC. Methods for dispersing carbon nanotubes for nanotechnology applications: Liquid nanocrystals, suspensions, polyelectrolytes, colloids and organization control. Int Nano Lett I. 2019;9(1):31 49.

14. Bacakova L, Pajorova J, Bacakova M, Skogberg A, Kallio P, Kolarova K, et al. Versatile application of nanocellulose: From industry to skin tissue engineering and wound healing. Pharm Nanotechnol. 2019;9(2):164.

15. Squinca P, Bilatto S, Badino AC, Farinas CS. Nanocellulose Production in Future Biorefineries: An Integrated Approach Using Tailor-Made Enzymes. ACS Sustain Chem Eng. 2020;8(5):2277-86.

16. Anirudhan TS, Shainy F, Thomas JP. Effect of dual stimuli responsive dextran/ nanocellulose polyelectrolyte complexes for chemophotothermal synergistic cancer therapy. Int J Biol Macromol. 2019;135:776-89.

17. Habib A, Khoda B. Development of clay based novel hybrid bio-ink for 3D bioprinting process. J Manuf Process. 2019;38:76-87.

18. Leszczyńska A, Stafin K, Pagacz J, Mičušík M, Omastova M, Hebda E, et al. The effect of surface modification of microfibrillated cellulose (MFC) by acid chlorides on the structural and thermomechanical properties of biopolyamide 4.10 nanocomposites. Ind Crops. 2018;116:97-108.

19. Ahmed A, Niazi MB, Jahan Z, Samin G, Pervaiz E, Hussain A, et al. Enhancing the Thermal, Mechanical and Swelling Properties of PVA/Starch Nanocomposite Membranes Incorporating gC 3 N 4. J Polym Environ. 2020;28(1):100-15.

20. Vineeth SK, Gadhave RV, Gadekar PT. Chemical modification of nanocellulose in wood adhesive. J Undergrad Chem Res Open. 2019;9(04):86.

21. Shahnaz T, Padmanaban VC, Narayanasamy S. Surface modification of nanocellulose using polypyrrole for the adsorptive removal of Congo red dye and chromium in binary mixture. Int J Biol Macromol. 2020;151:322-32.

22. Yao J, Fang W, Guo J, Jiao D, Chen S, Ifuku S, et al. Highly Mineralized Biomimetic Polysaccharide Nanofiber Materials using Enzymatic Mineralization. Biomacromolecules. 2020.

23. Rees VWM, Matsumoto EA, Gladman AS, Lewis JA, Mahadevan L. Mechanics of biomimetic 4D printed structures. Soft Matter. 2018;14(43):8771-9.

24. Ouyang L, Yao R, Zhao Y, Sun W. Effect of bioink properties on printability and cell viability for 3D bioplotting of embryonic stem cells. Biofabrication. 2016;8(3):035020 
25. Choi YJ, Kim TG, Jeong J, Yi HG, Park JW, Hwang W, Cho DW. 3D cell printing of functional skeletal muscle constructs using skeletal muscle-derived bioink. Advanced Healthcare Materials. 2016;5(20):2636-45.

26. Piras CC, Fernández-Prieto $S$, DeBorggraeve WM. Nanocellulosic materials as bioinks for 3D bioprinting. Bioact Mater. 2017;5(10):1988-92.

27. Sultan S, Siqueira G, Zimmermann T, Mathew AP. 3D printing of nano-cellulosic biomaterials for medical applications. Curr Opin Biomed Eng. 2017;2:29-34

28. Bernal PN, Delrot P, Loterie D, Li Y, Malda J, Moser C, et al. Volumetric bioprinting of complex living-tissue constructs within seconds. Adv Mater. 2019;31(42):1904209.

29. Gao G, Lee JH, Jang J, Lee DH, Kong JS, Kim BS, et al. Tissue engineered bio-blood-vessels constructed using a tissue-specific bioink and 3D coaxial cell printing technique: A novel therapy for ischemic disease. Advanced Functional Materials. 2017;27(33):1700798.

30. Daly AC, Freeman FE, Gonzalez-Fernandez T, Critchley SE, Nulty J, Kelly DJ. $3 \mathrm{D}$ bioprinting for cartilage and osteochondral tissue engineering. Adv Healthc Mater. 2017;6(22):1700298.

31. Chimene D, Lennox KK, Kaunas RR, Gaharwar AK. Advanced bioinks for 3D printing: A materials science perspective. J Bioeng. 2016;44(6):2090-102.

32. Groll J, Burdick JA, Cho DW, Derby B, Gelinsky M, Heilshorn SC, et al. A definition of bioinks and their distinction from biomaterial inks. Biof. 2018;11(1):013001.

33. Müller M, Öztürk E, Arlov $\varnothing$, Gatenholm P, Zenobi-Wong M. Alginate sulfate-nanocellulose bioinks for cartilage bioprinting applications.J Bioeng. 2017;45(1):210-23

34. Nguyen D, Hägg DA, Forsman A, Ekholm J, Nimkingratana P, Brantsing C, Kalogeropoulos T, Zaunz S, Concaro S, Brittberg M, Lindahl A. Cartilage tissue engineering by the 3D bioprinting of iPS cells in a nanocellulose/alginate bioink. Scientific reports2017;7(1):1-0.

35. Lu R, Zhang $X$, Fu L, Wang H, Briber RM, Wang H. Amorphous cellulose thin films. Cellulose. 2020;7:1-7.

36. Kargarzadeh $H$, loelovich M, Ahmad I, Thomas S, Dufresne A. Methods for extraction of nanocellulose from various sources. Handbook of Nanocellulose and Cellulose Nanocomposites. 2017;1:1-51.

37. Hussin MH, Trache D, Chuin CT, Fazita MN, Haafiz MM, Hossain MS. Extraction of cellulose nanofibers and their eco-friendly polymer composites. Mater Sci Eng C Mater Biol Appl. Springer, Cham. 2019;653-91.

38. Torres FG, Arroyo JJ, Troncoso OP. Bacterial cellulose nanocomposites: An allnano type of material. Mater Sci Eng C Mater Biol Appl. 2019;98:1277-93.

39. Du H, Liu W, Zhang M, Si C, Zhang X, Li B. Cellulose nanocrystals and cellulose nanofibrils based hydrogels for biomedical applications. Carbohydr Polym. 2019;209:130-44.

40. Manzetti S, Gabriel JC. Methods for dispersing carbon nanotubes for nanotechnology applications: Liquid nanocrystals, suspensions, polyelectrolytes, colloids and organization control. Int Nano Lett. 2019;9(1):3149.

41. Du H, Liu W, Zhang M, Si C, Zhang X, Li B. Cellulose nanocrystals and cellulose nanofibrils based hydrogels for biomedical applications. Carbohydr Polym. 2019;209:130-44

42. Tran TN, Paul U, Heredia-Guerrero JA, Liakos I, Marras S, Scarpellini A, et al. Transparent and flexible amorphous cellulose-acrylic hybrids. Int J Chem Eng Appl. 2016;287:196-204

43. Ajdary R, Huan S, Zanjanizadeh EN, Xiang W, Grande R, Santos HA et al. Acetylated nanocellulose for single-component bioinks and cell proliferation on 3D-printed scaffolds. Biomacromolecules. 2019;20(7):2770-8.

44. Kim BS, Kwon YW, Kong JS, Park GT, Gao G, Han W, et al. 3D cell printing of in vitro stabilized skin model and in vivo pre-vascularized skin patch using tissue-specific extracellular matrix bioink: a step towards advanced skin tissue engineering. Biomater Res. 2018;168:38-53.

45. Smandri A, Nordin A, Hwei NM, Chin KY, Abd Al, Fauzi MB. Natural 3D-Printed Bioinks for Skin Regeneration and Wound Healing. J Polym. 2020;12(8):1782

46. Serrano DR, Terres MC, Lalatsa A. Applications of 3D printing in cancer. J 3D Print Med. 2018;2(3):115-27.

47. Swaminathan S, Hamid Q, Sun W, Clyne AM. Bioprinting of 3D breast epithelial spheroids for human cancer models. Biofabrication. 2019;11(2):025003.

Article History: Submission Date : 03-10-2020; Revised Date : 23-11-2020; Acceptance Date : 09-01-2021

Cite this article: Ganpisetti R, Lalatsa A. Cellulose Bio-ink on 3D Printing Applications. J Young Pharm. 2021;13(1):1-6. 